Emilio La Parra, Fernando VII. Un rey deseado y detestado, Barcelona, TusQuets, 2018, 745 págs.

En la serie epistolar que el poeta Manuel José Quintana dirigió a su amigo y benefactor, Lord Holland, ofrecía una desoladora semblanza de Fernando VII:

La disposición de su ánimo ha debido ser siempre opuesta a un orden cualquiera liberal, y esto en un grado más alto que lo son los demás príncipes por el tenor general de su condición y sus principios. Consideradle desde niño mal querido de sus padres, eclipsado y desairado por el arrogante visir [Manuel Godoy], alejado de todo influjo y representación, contrariado casi siempre en sus gustos y aficiones, observado en su conducta, rodeado de espías, y amagado muchas veces, según se decía en aquel

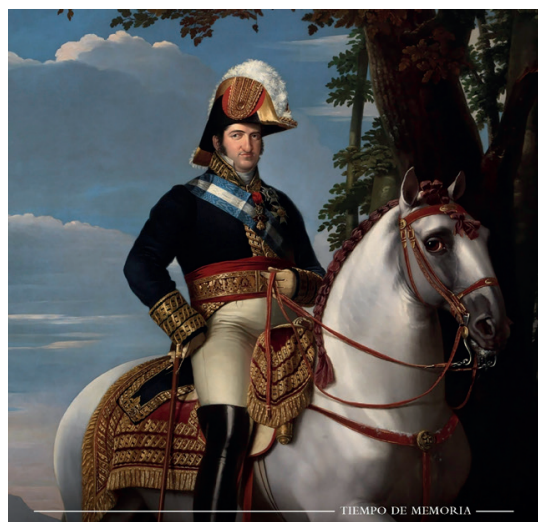

Emilio La Parra

\section{FERNANDO VII}

Un rey deseado y detestado

XXX PREMIO COMILLAS tiempo, de perder alevosamente la vida para que perdiese la corona [...]. Añadid las sugestiones viciosas de las pasiones e intereses que han estado sin cesar combatiéndose alrededor suyo, los consejos contradictorios, las delaciones continuas, las perfidias e inconsecuencias que de cuando en cuando ha experimentado en sus mismos favoritos; y todo junto os dará fácilmente la razón de esta propensión recelosa, de esta falta de confianza que se advierte habitualmente en el Rey de España, de este anhelo de mando exclusivo y absoluto, de esta contradicción constante y manifiesta a toda idea o propuesta de régimen constitucional ${ }^{1}$.

El retrato ofrecido por Quintana — que sería procesado por el inicuo Rey por sus ideas liberales - redundaba en algunos lugares comunes que el liberalismo español se empeñó en sostener: la imagen de un Fernando VII engañado y víctima de malos educadores y peores consejeros. Con ello se acababa con-

1 Carta a Lord Holland (25 de diciembre de 1823), en Manuel José Quintana, Cartas a Lord Holland sobre los sucesos políticos de España en la segunda época constitucional, edición de Manuel Moreno Alonso, Sevilla, Alfar, 2010, págs. 144-145. 
virtiendo de algún modo al verdugo en víctima, justificando (o al menos explicando) la conducta de uno de los Reyes de peor fama en España. Imagen que se ganó a pulso.

Elaborar una biografía seria, rigurosa y carente de prejuicios era sin embargo, algo que desde hace tiempo merecía la controvertida figura de Fernando VII. Los intentos de Federico Suárez dirigidos a rehabilitar al «Deseado» rescatando su documentación no cumplieron ese propósito, precisamente por estar marcados desde un comienzo por un objetivo hagiográfico. Sí lo hace - y con un resultado espectacular- Emilio La Parra. Y no podría haber un historiador más a propósito para tal cometido: el profesor La Parra conoce a la perfección el contexto político de finales del XVIII y primer tercio del XIX, y es el máximo experto en la figura de Manuel Godoy, a la que dedicó la mejor biografía que se ha escrito sobre el valido, y que es capital para entender al propio Fernando VII. Precisamente su conocimiento de Godoy muestra otra virtud de Emilio La Parra para asumir el reto de enfrentarse a la figura de Fernando VII: no suele buscar personajes con unas ideas bien definidas (como Agustín Argüelles), sino que prefiere aquellos con mayor complejidad (como Joaquín Lorenzo Villanueva); y tampoco apuesta por figuras que han pasado a la historia investidos con una buena fama (como Jovellanos), sino que se inclina hacia sujetos con escasa estima por parte de la historiografía.

En el caso de Manuel Godoy, Emilio La Parra demostró que buena parte de esa mala imagen que lo acompañaba era fruto de un interés difamatorio que precisamente tuvo a Fernando VII y su corte como parte de los causantes, y que luego resultó todavía más explotado por el primer liberalismo. Sin embargo, su biografía de Fernando VII demuestra que para el hijo de Carlos IV no hay redención posible. Y lo hace sin prejuicios, sin planteamientos previos... con la objetividad que proporcionan años de intenso trabajo, inmersión en una extraordinaria cantidad de fuentes archivísticas, manejo de la bibliografía más actual y, en fin, una capacidad de análisis y deducción de la que ha dejado constancia desde su tesis doctoral que, a mi modo de ver, sigue siendo el mejor estudio que hasta la fecha se ha realizado sobre la cuestión religiosa en las Cortes de Cádiz.

El libro de Emilio La Parra engancha ya desde la primera página. Es esta una virtud suya, una seña de identidad con la que siempre sella sus obras, que no solo ofrecen una vasta erudición, sino que la revisten con un estilo fluido y ameno que llama constantemente a seguir leyendo. Se trata de una obra al alcance de todos, y que colma por igual las expectativas de especialistas que las del lector profano interesado en nuestro pasado. Algo extremadamente difícil de conseguir, y en lo que Emilio La Parra es un auténtico maestro. Un dato erudito o una conclusión brillante siempre aparece a renglón seguido acompañado de 
una anécdota, un comentario de la época, una frase ingeniosa o una descripción sustanciosa.

$$
* * *
$$

Tenía razón Quintana: para entender a Fernando VII es menester indagar en su infancia y etapa formativa, algo a lo que se dedican las primeras páginas del libro de Emilio La Parra. Tras el fallecimiento de sus dos hermanos varones, el infante Fernando se vio sometido a una estrecha tutela de sus progenitores, temerosos de perder también al siguiente en la línea de sucesión al trono. La educación del infante fue confiada a varios preceptores, entre quienes destaca la figura de Escoiquiz por la estrecha relación que mantendría con Fernando VII en el futuro, convirtiéndose en uno de sus más cercanos consejeros. Persona acostumbrada a las maniobras torticeras, escurridizo y engañoso, lo cierto es que Escoiquiz poseía algunos de los defectos que más tarde caracterizarían al inicuo monarca.

La ya referida posición privilegiada que confiere a Emilio La Parra el ser el máximo experto en Manuel Godoy proporciona a su libro una solvencia interpretativa de Fernando VII que no podría obtenerse por otras vías. El profesor La Parra pone de relieve la tensa relación que siempre existió entre el infante y el valido, aunque más por envidia del primero que por actos del segundo. Rencoroso con el protegido de su padre, el infante Fernando esperó al momento adecuado para propiciar su caída. Lo intentó primero, con nula fortuna, en la trama de El Escorial, que dio lugar a uno de los más patéticos episodios de la monarquía española. Las maniobras del infante Fernando para contraer matrimonio con una princesa gala - a fin de aproximarse a Napoleón, y en contra de la voluntad de sus padres—- y la vergonzosa forma en la que se destapó la conjura (con Carlos IV registrando al infante para hallar en sus bolsillos la documentación que le implicaba) solo fue superada en torpeza por la conducta del Rey, al implicar a Napoleón directamente en el asunto (lo que a punto estuvo por acabar con una declaración de guerra anticipada) y por inculpar públicamente ante la nación al infante, para concederle a renglón seguido su perdón. Circunstancia que solo sirvió para que el infante Fernando - que en su cobardía no dudó en delatar a los restantes conspiradores — saliese con una imagen reforzada, en tanto que la de Godoy, y el propio Carlos IV, resultó todavía más perjudicada.

Fracasada la intentona de El Escorial, el infante Fernando simuló un mayor acercamiento a Godoy solo para allanar el camino a su siguiente golpe, que tendría lugar en 1808, a través del conocido Motín de Aranjuez. Emilio La Parra desmonta muchos de los mitos que circularon en torno a esta algarada y, con 
una narración casi forense de los hechos, traza una espléndida semblanza de lo que sucedió en tres días que dieron un vuelco a la monarquía española. En este discurso no se olvida de tener siempre presente cómo evaluaba Napoleón los acontecimientos a medida que estos se iban produciendo, aspecto de extremo interés, habida cuenta de la presencia de las tropas del Corso en suelo español - merced al tratado de Fontainebleau - que preparaban el camino para una invasión simulada a través de la lucha contra el enemigo inglés.

Tras renunciar Carlos IV a la Corona, Emilio La Parra recuerda cómo el nuevo rey adoptó una serie de medidas populares, inspiradas por una inteligencia que no siempre acompañaría a las sucesivas medidas del nuevo monarca. La idea de Fernando VII era aparecer como el regenerador de España, deshaciendo muchas de las medidas que él interesadamente imputaba a Godoy, como el encierro de Jovellanos y el destierro de Cabarrús, dos de los ilustrados más prominentes. Inteligente pareció también la selección de los nuevos ministros — «hombres de mérito», como recuerda La Parra— aunque de poco sirvió, habida cuenta de que el Rey prefirió rodearse de una suerte de gabinete privado de su mayor confianza —integrado por Escoiquiz, Infantado y San Carlos_, cuya mera existencia «delataba la pretensión de Fernando VII de gobernar personalmente con plena autoridad» (pág. 153).

La disputa entre Carlos IV y Fernando VII no tardaría en convertirse en una contienda a tres bandas, merced a la aparición en la trama de un nuevo actor: Napoleón. Las intenciones ocultas del Corso pasaban por anexionar a Francia los territorios españoles colindantes —incluida Cataluña — pero su plan pareció complicarse tras el Motín de Aranjuez. Emilio La Parra traza con todo lujo de detalle los movimientos del Corso para recuperar la iniciativa, citando a Fernando VII para que se reuniese con él; algo que, por otra parte, necesitaba imperiosamente el recién erigido monarca: al no haber obtenido el trono como estipulaban las Leyes Fundamentales, y ante el riesgo más que plausible de que Carlos IV quisiera recuperar el trono, Fernando necesitaba imperiosamente el espaldarazo del Corso, algo que consideraba como única vía para legitimar su reinado.

La narración del viaje de Fernando VII al encuentro de Napoleón que hace Emilio La Parra no tiene desperdicio: el rey español iba llegando a los sucesivos parajes de la cita — Burgos primero, Vitoria después— solo para hallarse con la ausencia del Emperador. Porque la intención de este era bien clara: no moverse de Francia y atraer allí al incauto Fernando VII. Aunque el monarca español dudó en proseguir el viaje —aconsejado entre otros por Urquijo-, el emisario de Napoleón, Savary, le dejó claro que su incomparecencia sería interpretada por Napoleón como circunstancia que legitimaba a Carlos IV como rey español. 
De ahí que, sin pensárselo dos veces, Fernando VII acabase por completar el trayecto hasta reunirse con Bonaparte en Bayona.

Lo que vino después solo puede calificarse como uno de los episodios más vergonzosos de la monarquía española: las llamadas «renuncias» o «abdicaciones de Bayona» supusieron un mercadeo infame de la Corona de España, cedida de Fernando VII a su padre, de este a Napoleón y del Corso a su hermano, investido como José I. Emilio La Parra lo narra de forma magistral, demostrando cómo Napoleón orquestó la trama: «Carlos IV y Fernando VII —señala— iban entrando con notable facilidad en el drama compuesto por Napoleón» (pág. 175). Resignado a no ocupar más el trono de España, Fernando VII se volvió más histriónico si cabe a la hora de humillarse ante los Bonaparte, lo que incluía no solo a Napoleón, sino a su hermano José, al que se dirigiría como «Su Majestad Católica».

El período que sigue ha sido silenciado por la mayoría de la historiografía que, centrada en los importantísimos acontecimientos que acaecían en España en ausencia del rey (Guerra de la Independencia, formación de las Juntas Provinciales y de la Junta Central, reunión de las Cortes de Cádiz y aprobación de la Constitución del 12) silencian qué sucedió con el pérfido rey en el ínterin. Emilio La Parra subsana esta omisión con un relato vívido de la estancia de Fernando VII en Valençay, dedicado al ocio (que incluía cambiar los retratos del palacio por otros de temática religiosa, amén de reemplazar la biblioteca de Talleyrand por otra cuyos ejemplares más notables destaca el profesor La Parra) rodeado de su séquito que, no obstante, abandonó al Rey por imposición de Napoleón, que temía intrigas. Sospecha nada desacertada, a tenor de los intentos del Rey de escaparse de la lujosa prisión en la que se hallaba confinado.

Por supuesto, no se olvida Emilio La Parra de narrar cuanto estaba aconteciendo por esas mismas fechas en España, pero, demostrando lo bien asido que tiene el hilo de Ariadna, lo enfoca hacia el propio Fernando VII. Así lo hace en el brillante epígrafe que dedica a las decisiones que en las Cortes de Cádiz se adoptaron sobre el Monarca, acordando la nulidad de cuanto decidiese Fernando VII en cautividad. Obviamente, los vergonzosos tejemanejes de las renuncias de Bayona tendrían también su impacto en el articulado de la Constitución que proyectaron, al prohibir al monarca en lo sucesivo «ausentarse del reino sin consentimiento de las Cortes», ni «enajenar, ceder, renunciar o en cualquiera manera traspasar a otro su autoridad real» (art. 172).

Pero, en realidad, lo que más habría de molestar a Fernando VII era la limitación a una autoridad que él consideraba absoluta e indiscutible. La Constitución de Cádiz estaba concebida como un cortafuegos frente al poder regio. Ya el proyecto constitucional de Álvaro Flórez Estrada — gestado en 1809, 
enviado a la Junta Central y publicado en Londres - contaba con un artículo relativo a las restricciones regias, que posiblemente influyó en el artículo 172 de la Constitución gaditana; pero esta última las sublimó, al punto de que Antonio Capmany se quejó en las Cortes del escaso decoro con el que se trataba la dignidad real: «Me ha causado grande extrañeza — recriminaba el diputado catalán- en todas las sesiones anteriores oír de boca de todos los Sres. Diputados que han hablado usar de la voz freno, freno y más freno; palabra que me parece muy indecorosa, y a la cual se debe sustituir otra más templada, como barrera, límite, etc. Parece que vamos a enfrenar un caballo desbocado, o a encadenar un ferocísimo león».

No debe extrañar que el pérfido Fernando VII —que había seguido de lejos los avatares de las Cortes gaditanas en su ausencia- se mostrase hostil contra aquella magna obra que minaba su soberanía. Emilio La Parra narra con detalle el intento de Napoleón en 1813 de buscar una salida digna a su inevitable derrota militar y política, suscribiendo un tratado con Fernando VII que excluyera a los británicos a cambio de restaurar al Borbón al frente de la Corona española. Como recuerda Emilio La Parra, la regencia rehusó ratificar el tratado, citando el decreto de 1 de enero de 1811 que anulaba cuanto negociase el Rey en su cautiverio.

Truncada esta última maniobra de Napoleón, Fernando VII regresó a España con la tutela de los británicos, a los que había insinuado la posibilidad de instaurar unas Cortes bicamerales. Una promesa vacua - como tantas otras del pérfido Rey_ puesto que su única intención era la de derogar de un plumazo la Constitución de Cádiz, perseguir a sus autores y reinstalarse en el trono como rey absoluto.

Lo que siguió fueron seis años de gobierno absoluto... más que antaño, basado en el absolutismo ilustrado de inspiración iusracionalista, entremezclada con una teoría tan distante de aquella como era la teocrática contrarrevolucionaria. Una situación sin precedentes en España que lleva a Emilio La Parra a sentenciar, con razón, que «Fernando VII no fue un rey absoluto como lo fueron sus antepasados [...]. El centro del poder quedó en las manos del rey y de un pequeño número de ministros y consejeros [...]. El resultado fue una nueva política $[\ldots]$ que $[. .$.$] no tenía otro límite que la voluntad real» (pág.$ 280). Un gobierno además sustentado en la mitificación de la imagen del Rey durante su cautiverio - de la que los propios liberales fueron en buena parte responsables - y que Fernando VII supo explotar - y sacarle incluso provecho económico a través de «donativos» que recibía de sus súbditos, a pesar de las penurias de la postguerra- Y su imagen pública no hacía sino acrecentarse, en buena parte gracias a los sermones de sacerdotes que llegaban a comparar 
al Rey con David y Moisés, y viendo en él a quien traería la «resurrección» (no regeneración o renovación) de España.

Pero esa «resurrección» no estaba exenta de venganza: el Rey hizo de la persecución de los liberales una de sus principales enseñas, a pesar de las dificultades para procesarlos, al no haber incurrido en delitos tipificados como tales por la entonces vigente legislación criminal. Incapaz de esperar a que los procedimientos se resolviesen, el propio Fernando VII dio muestras de su modo de actuar condenando él mismo el 15 de diciembre de 1815 a los liberales detenidos el año anterior. En los años siguientes las condenas se sucedieron, incluyendo la pena capital a Porlier, Lacy y Richart, por delito de «lesa majestad». Su hostilidad no se ciñó sin embargo a los liberales, sino que incluyó a los afrancesados, a los que no permitió regresar a España.

La vengativa actitud de Fernando VII le valió en Europa la justificadísima imagen de un monarca cruel e ingrato. La buena reputación de que gozaba en España (excepto entre los liberales, que sufrían su iniquidad) discrepaba con la que tenía más allá de las fronteras; imagen negativa que habría de empeorar con el restablecimiento del odiado Tribunal de la Inquisición. Como recuerda Emilio La Parra —el mejor conocedor de la Inquisición en el XVIII, a la que dedicó, junto con María Ángeles Casado, un magnífico libro (La Inquisición en España. Agonía y abolición, 2013)—, Fernando VII no se limitó a restaurar sin más el Santo Oficio, sino que lo instrumentalizó, empleándolo no ya como salvaguardia de la fe, sino como mecanismo represor de la disidencia política: de ahí que sus objetivos principales fuesen tanto los masones como los planes insurreccionales del liberalismo.

La vuelta a la vida de la Inquisición no fue la única prebenda obtenida por el clero: también obtuvo el restablecimiento de las Órdenes Religiosas —con especial relevancia para la Compañía de Jesús, dedicada al adoctrinamiento de la juventud - a las que devolvió los bienes nacionalizados por José I. De este modo, se fijaba una alianza entre el trono y el altar, muy conveniente para el absolutismo de Fernando VII.

Desde un plano político e institucional, Fernando VII potenció el papel de los ministros en detrimento del sistema polisinodial, siendo especialmente damnificado el Consejo de Castilla que, a pesar de mantener sus funciones jurisdiccionales, quedó políticamente arrinconado. El fortalecimiento de los ministerios era, en realidad, un medio más para sustentar el absolutismo, ya que garantizaba la intervención directa del monarca, aunque estuvo caracterizado por una notable inestabilidad: recuerda Emilio La Parra que en los seis años, la mayoría de los ministros no llegó a cumplir siquiera un año en el cargo. Al frente de estos ministerios rotativos se hallaban algunos absolutistas radicales, realistas mode- 
rados y, como pieza discordante, un liberal: Martín de Garay, que había formado parte entre 1808 y 1810 de la Junta Central. No obstante, la interinidad de los ministros no se notó mucho en las decisiones gubernamentales, puesto que en realidad estas las adoptaba directamente el rey junto con un grupo selecto de consejeros que formaron la llamada «camarilla» — cuya composición exacta se desconoce, si bien posiblemente Ostolaza, Escoiquiz y Gravina se hallaran entre sus integrantes-.

Este gobierno absoluto del Rey era cuestionado entre los españoles y ninguneado por las potencias extranjeras. Entre los primeros, el Empecinado y Álvaro Flórez Estrada redactaron sendas representaciones al rey cuestionando su modelo de gobierno y proponiendo el retorno al régimen representativo. Sus escritos mantenían sin embargo al rey como cabeza del Estado; algo que no sucedía con el llamado «plan Beitia», un intento de alzamiento militar organizado en 1819 que pretendía derrocar a Fernando VII e instaurar una Constitución basada en las teorías de Benjamin Constant — plan que fracasó por la traición de uno de sus cabecillas, el conde de la Bisbal—. Fuera de España, las potencias extranjeras trataron al país como una "potencia de segundo orden", en palabras del embajador español ante el Congreso de Viena, Pedro Gómez Labrador. De ahí que el otrora orgulloso imperio español no lograse sacar tajada del nuevo orden político europeo, a pesar de haber contribuido decisivamente a la caída de Napoleón; pero es que, como añade Emilio La Parra, ese imperio estaba a punto de desmoronarse con la pérdida definitiva de los territorios ultramarinos.

No se olvida Emilio La Parra del contexto familiar del rey. Fue en el sexenio absolutista cuando contrajo nuevas nupcias, esta vez con Isabel de Braganza; y en esa misma etapa también se produjo un acercamiento a su padre, Carlos IV, reconciliado con quien le privase del trono, aunque la venalidad fuese parte de esta nueva relación amistosa: Fernando VII aprobó el conocido como «Tratado de Alimentos» que procuraba al rey depuesto los medios económicos que requería su dignidad.

La siguiente etapa en el reinado de Fernando VII fue quizás la más irritante para el pérfido monarca. En 1820, tras el pronunciamiento de Rafael del Riego en Cabezas de San Juan, se obligaba al rey a jurar la Constitución de Cádiz que tanto odiaba, y a convivir con gobiernos integrados por liberales, a los que había hostigado durante más de un lustro: no en balde, el primer gobierno constitucional del Trienio Liberal (1820-1823) fue conocido como el de «los presidiarios», por haber estado sus integrantes confinados en prisiones por orden de Fernando VII.

En realidad, el Trienio fue el primer momento en el que la Constitución de Cádiz pudo aplicarse de verdad. No había sucedido así durante el breve período 
que transcurrió desde su aprobación en 1812 hasta su anulación regia en 1814: en ese breve período, la coyuntura bélica impidió que se pusiera en planta parte del entramado institucional (como la administración de justicia), amén de que la ausencia del Rey (sustituido por una regencia) y el carácter constituyente de las Cortes distorsionaron el sistema de distribución de poder que establecía la Constitución.

Durante el Trienio, o al menos en su primer año y medio de vida, los liberales trataron de disimular la conocida inquina del rey hacia la Constitución: les interesaba propagar la ficticia imagen de un monarca dispuesto a respetar la norma fundamental, pero se cuidaron de poner rápidamente en planta al Consejo de Estado, como órgano consultivo del Rey, escogido por las Cortes, a fin de controlar sus decisiones. Sin embargo, los propios liberales se habían fragmentado en dos alas (exaltados y moderados) y esta división acabó lastrando sus intentos por meter en cintura al monarca. Los primeros no renunciaron a algaradas ante el Palacio Real cuando les disgustaban las decisiones del rey (por ejemplo, con la destitución del gabinete Evaristo San Miguel, relatada con detalle en el libro), en tanto que los segundos proyectaban la sustitución de la Constitución de Cádiz por un texto menos radical, basado en el liberalismo doctrinario. La desafección moderada de la Constitución hacía poco convincente que trataran de imponerla al rey. En realidad, la tercera esposa de Fernando VII, María Josefa Amalia de Sajonia, también parecía situarse políticamente en un complicado punto intermedio, como demuestran las Cartas de la reina Witinia que Emilio La Parra resume con maestría: aunque denostaba en ellas el régimen constitucional y la actuación de los liberales, tampoco le agradaba la represión que había acometido Fernando VII durante el sexenio absolutista.

Pero cualquier pretensión del liberalismo de que Fernando VII acatase la Constitución de Cádiz —o en general cualquier otra que la reemplazase - estaba condenada al fracaso. En un epígrafe magistral, Emilio La Parra demuestra cómo el inicuo rey fue protagonista directo de los intentos para derrocar el régimen representativo. Él mismo aprobaba y financiaba los planes que luego eran dirigidos por Ugarte, Eguía y el marqués de Mataflorida y ejecutados por las juntas realistas provinciales y locales. Al mismo tiempo, elaboraba una lista de sus acólitos y de sus enemigos, a fin de tenerla pronta para cuando llegase el momento propicio para su venganza. No obstante, las intentonas golpistas de Fernando VII (en enero de 1821 y en julio de 1822) fracasaron, lo que le obligó a depositar sus esperanzas en la intervención extranjera.

A finales de 1822 y comienzos de 1823 cualquier intento de mantener una mínima apariencia de respeto entre el gobierno liberal y el rey resultaba imposible. El monarca realizó continuos desplantes a las Cortes y se deshizo de 
Gobiernos que contaban con el apoyo parlamentario. Pero la situación llegaría a su límite en 1823, cuando, con el ejército de la Santa Alianza a las puertas, las Cortes acordaron el traslado de Fernando VII a Sevilla, algo a lo que el Rey se opuso. En una decisión sin precedentes, las Cortes incapacitaron al Monarca, pero lo cierto es que la posición del gobierno liberal era ya extremadamente débil: sabedor de que la caída del régimen constitucional resultaba inevitable, trató al menos de pactar con el rey la sustitución de la Constitución de Cádiz por otra más moderada. Vacuo intento: respaldado por los Cien Mil Hijos de San Luis, Fernando VII solo deseaba la liquidación del régimen constitucional. Por segunda vez.

El último capítulo del libro se dedica, obviamente, a la Ominosa Década (1823-1833) que abarca desde el fin del Trienio Liberal hasta el fallecimiento del monarca. Una etapa definida por Emilio La Parra como la de consolidación del «rey neto», es decir, de un absolutismo sin más límites que los condicionantes fácticos, que no institucionales, que pesaban sobre el Rey.

Como bien señala el profesor La Parra, esos condicionantes fueron dos: uno externo y otro interno. El primero derivaba del interés de Francia por que España contase con un sistema constitucional que imitase el modelo francés de 1814, a saber, una Carta Otorgada que estableciese un sistema representativo bicameral, de corte británico, y en el que las clases privilegiadas pudieran participar en el gobierno nacional. Fernando VII seguía sin embargo empecinado en truncar esta posibilidad, lo que le valió una pésima imagen no solo ante su libertador, Angulema, sino también entre reputadas personalidades del ultrarrealismo francés, como Chateaubriand.

Internamente, las lindes absolutistas del rey se hallaban en su recelo ante los realistas más extremos. De hecho, ante los excesos en que incurrían —con una constante represión contra los liberales- Angulema había llegado en 1823 a acordar un decreto por el que prohibía a las autoridades españolas realizar arrestos sin la correspondiente autorización del comandante militar francés del distrito. Por su parte, Luis XVIII había pedido prudencia al rey español, y le recomendó amnistiar a sus enemigos políticos, algo a lo que Fernando VII se negó. No obstante, tampoco se decantó por el revanchismo radical que pretendían los realistas más extremos; más bien apostó por rodearse de realistas moderados, lo que dio lugar a una desafección por parte de ese otro sector más radicalizado a los que quedaba, en certeras palabras de Emilio La Parra, el «sentimiento de la vitoria mutilada» (pág. 488). Ello no quiere decir que Fernando VII suavizase su antiliberalismo: a pesar de que se negó a restaurar la Inquisición — como pretendían los realistas radicales_ puso en planta una policía dedicada principalmente a la persecución de la disidencia política. 
A nivel institucional, una de las aportaciones más relevantes de esta etapa fue sin duda el nacimiento del Consejo de Ministros. Ciertamente ya habían existido algunos precedentes $-\mathrm{o}$ al menos intentos- durante las Cortes de Cádiz y el Trienio Liberal; y el propio Fernando VII había apuesto en planta en 1815 la Junta Suprema de Estado, órgano originariamente surgido a finales del XVIII (1787-1792). Sin embargo, el 19 de noviembre de 1823 daría forma a un Consejo de Ministros destinado a tratar los asuntos de interés general. A pesar de tamaña novedad, lo cierto es que el modus operandi del rey no varió sustancialmente: Fernando VII seguía adoptando las decisiones principales directamente, o despachando individualmente con sus ministros. De este modo, se truncaba cualquier expectativa de modernidad administrativa.

Esta falta de progreso fue cuestionada por Javier de Burgos en un atrevido informe en el que recalcaba algunos de los puntos negros del régimen. Más atrevido fue un proyecto elaborado durante el exilio en 1826 por Juan de Olavarría, autor años después del proyecto constitucional de La Isabelina (1834). El llamado «plan de Julio» diseñado por Olavarría no contenía en este caso texto constitucional alguno, pero al menos proponía una amnistía a los liberales, la libertad de prensa y la creación de un Consejo de Estado de elección provincial que actuase a modo de órgano representativo.

El plan de Olavarría era - como certeramente lo califica Emilio La Parra-, «descabellado» y de resultas condenado al fracaso. A pesar de estas tentativas, Fernando VII no se movió un ápice de sus planteamientos absolutistas y ya en los últimos años, tras su matrimonio con María Cristina de Borbón, se ocupó de procurar que a su muerte su hija Isabel pudiese reinar con su mismo talante autoritario, publicando en 1830 la Pragmática Sanción que daría fuerza legal al acuerdo que habían aprobado las Cortes en 1789 - las mismas Cortes que lo habían proclamado Príncipe de Asturias- aboliendo la Ley Sálica.

$* * *$

En el año 2008 tuve ocasión de invitar a Emilio La Parra a un curso de verano que organizamos en Gijón para conmemorar los inicios del constitucionalismo español. Recuerdo que por aquel entonces, Emilio me hizo partícipe de algunos de sus descubrimientos sobre Fernando VII, de quien había decidido hacer una biografía. Diez años después, su esperado libro ha visto la luz. El tiempo transcurrido refleja el concienzudo, minucioso, incluso diríase detectivesco trabajo que ha hecho Emilio La Parra. No es hombre que se prodigue a escribir un libro cada año: los suyos son trabajos de enorme calado, fruto de pesquisas cuidadosas y reflexiones meditadas. Por eso, cada libro de Emilio La Parra es un regalo 
para el lector. Se convierte siempre en una obra de referencia que, además, agota el tema. Si su biografía sobre Godoy marcó un hito para los estudios del siglo XVIII, su semblanza de Fernando VII hace otro tanto para la historiografía del tránsito entre el siglo de la Ilustración y la Edad Contemporánea. Un lujo de cuya lectura no solo se aprende muchísimo, sino que se disfruta como si de una novela se tratase.

Ignacio Fernández Sarasola 